\title{
Virtual Collaboration with Mobile Social Media in Multiple-Organization Projects
}

\author{
Zhaojun Yang \\ Xidian University \\ zhaojunyang@xidian.edu.cn
}

\author{
Jun Sun \\ University of Texas Rio \\ Grande Valley \\ jun.sun@urtgv.edu
}

\author{
Yali Zhang \\ Northwestern Polytechnical \\ University \\ zhangyl@nwpu.edu.cn
}

\author{
Ying Wang \\ University of Texas Rio \\ Grande Valley \\ ying.wang01@utrgv.edu
}

\begin{abstract}
This study investigates the use of mobile social media as emerging collaboration tools by virtual teams. Based on the construal level theory, it develops a research model hypothesizes that collaboration tool effectiveness influence contextual performance and task performance through the mediation of procedure agreeability. In addition, geographic dispersion, team size and project duration serve as moderators as they reflect virtual collaboration complexity. Empirical findings support most hypothesized relationships. Theoretical and practical implications are discussed.
\end{abstract}

\section{Introduction}

Social media changes the way how people communicate with each other in personal and professional lives [19]. The latest ubiquitous form of social media based on mobile technologies allows people to stay connected anytime and anywhere [7]. Meanwhile, organizational tasks are increasingly dependent on social interactions as they become more complex and team-based [32]. Organizations adopt mobile social media to facilitate team building and task collaboration beyond face-to-face meetings [37].

Mobile social media support work-related communications within and across organizational boundaries [13]. Through the mediation of technologies like mobile instant messaging (IM), project team members, external partners, customers, suppliers and other stakeholders are able to collaborate with each other [21, 35]. For multiorganization projects that involve cross-boundary and cross-space collaboration, in particular, mobile social media can greatly enhance team communications, relations, and performances [31, 41].

Though existing studies provide helpful insights on mobile social media usage and outcome in virtual teams, there is still a research gap in between. It is possible that two comparable multi-organization projects use the same virtual collaboration tool, yet one becomes successful and the other fails. Based on the construal level theory, this study investigates the group dynamics and project characteristics that make the differences in the relationship between collaboration tool effectiveness and task performance. The findings may shed light on the best practices on team utilization of mobile social media as virtual collaboration tools for the success of multiorganization projects that vary in complexity.

\section{Research Background}

\subsection{IS Effectiveness}

It is almost impossible to optimize virtual team operations without understanding the technological effects of collaboration tools. The concept of information systems (IS) effectiveness captures how well technologies facilitate the completion of user tasks [28]. Researchers operationalize the concept to empirically examine the effectiveness of traditional organizational systems like transaction processing systems as well as collaboration tools like group decision-support systems [59, 71].

In most of studies, IS effectiveness is used as the dependent variable similar to user satisfaction but of a wider scope [61]. Yet, its conceptualization is closely tied to the investigation of ultimate IS success in terms of net system benefits from task accomplishment [20]. More recently, researchers start to use it as an independent variable to predict the outcome of system usage such as task productivity [62]. Yet few have addressed the effectiveness of collaboration tools in virtual teams.

The relationship between IS effectiveness and success may not be as direct as it appears, especially in group settings. In addition to performance contribution, IS effectiveness is also closely related to user experience $[44,12]$. In the virtual collaboration facilitated by mobile social media, task 
accomplishment depends on how well team members get along and work together through technology mediation.

\subsection{Group Dynamics}

How the members of a social network interact with each other for common goals concerns the concept of group dynamics [5]. It demands the understanding of collective whole rather than individual behavior [33]. Once a group forms, its functioning is shaped primarily by group structure and team performance, the iterative interplay between which drives the evolvement of group dynamics [25].

Group structure defines the relations among team members [68]. It captures the roles and norms underlying the communication patterns within a group [36]. Rarely discussed or written down but emergent from social interactions, such a structural influence is a fundamental aspect of group dynamics that guide the behavior of individual members [30]. For virtual teams based on mobile social media, the formation of group structure depends on how members use available technological features [26].

Rather than the simple aggregation of individual efforts, team performance is a synergy of performance gains from social facilitation in collaboration [25]. Social facilitation pertains to mutual support, encouragement and stimulation that motivate members in a group to do better [29]. Such an aspect of team performance can be denoted as contextual performance, which is distinguished from task performance [15]. Thus, team performance comprises two aspects: contextual performance related to social facilitation and task performance related to performance gains. For a multiorganization project facilitated by mobile social media, contextual performance is essential for team collaboration leading to task performance.

\subsection{Project Characteristics}

Compared with face-to-face teamwork, virtual collaboration through the mediation of computer technology is more challenging due to the effect of distance that filters out most of the social cues such as facial expression and body language $[8,66]$. It is essential to develop relationships, share understanding, and build trust among the members of virtual teams for their collaboration with each other [52]. The more physically dispersed they are, the smaller chance there is for them to know and meet with each other in person. The primary characteristic of multi-organization projects, therefore, is geographic dispersion.
In addition to the spatial factor, the temporal factor also concerns the success of multi-organization projects. The longer a project lasts, the more chance it is exposed to uncertainties and risks associated with the changes in team composition, task requirement and external environment [34]. Thus, keeping the project duration as short as possible (under 3 years, 1 year preferable) is a major success factor [16]. Meanwhile, it takes time to develop relationships and trust among team members, which is critical for group cohesion, satisfaction and performance [11]. Thus, project duration may have some mixed effects on team performance.

Finally, team size is another project characteristic pertaining to the complexity of virtual collaboration. The increase in team size typically makes it more difficult for members to interact with each other and participate in teamwork, leading to negative consequences such as social loafing, member dissatisfaction, and group incoherence [14, 45]). Thus, team size is found to have a negative impact on team performance and project success [2]. Similar to project duration, however, team size may also bring benefits like the collection of diversified information/views and the access to various capabilities [46].

\section{Theoretical Framework}

In multi-organization projects, team members work together beyond spatial, temporal and organizational boundaries through the facilitation of technologies like mobile social media. They develop the norms underlying the communication patterns after their teams are formed, and each team is unique depending on technological functionalities, member compositions and task settings [42]. Figure 1 conceptualizes IS effectiveness, group dynamics and project characteristics in the context of virtual collaboration to understand their influences on team development.

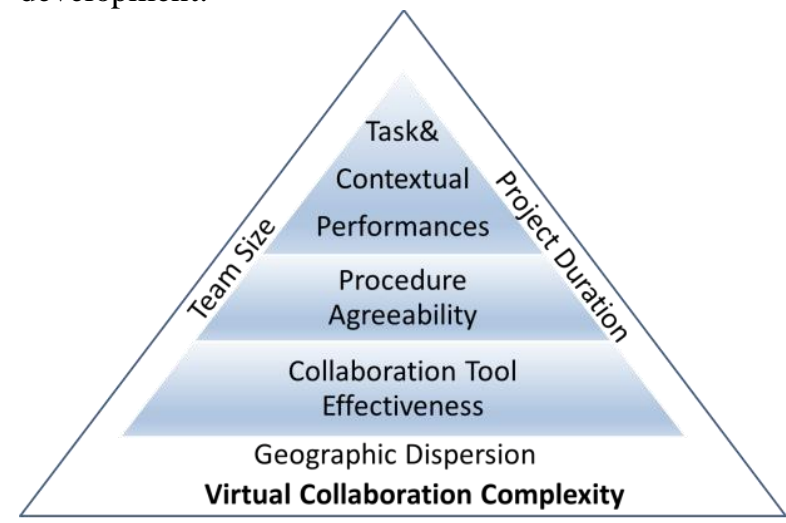

Figure 1. Virtual team development 
Derived from IS effectiveness, collaboration tool effectiveness captures how well technologies like mobile social media facilitate the communication and cooperation among the members of virtual teams. The use of new-generation collaboration tools induces different procedures of information sharing and decision-making in virtual teams [64]. Procedure agreeability taps how receptive team members are to the group structure aspect (i.e. communication patterns) of group dynamics as shaped by the use of technology. The team performance aspect of group dynamics comprises contextual performance concerning relationship building and mutual support, and task performance concerning ultimate deliverables. Finally, the technology-facilitated group dynamics evolve in virtual collaboration complexity associated with geographic dispersion, project duration and team size.

Construal level theory provides a useful lens to look into virtual team development in terms of the relationships among relevant constructs. The theory posits that the concreteness of people's thinking about something depends on its psychological distance to them [63]. The most important dimensions of psychological distance include temporal, spatial, social and hypothetical distances [6]. Concerning the concreteness of collaborative activities to multi-organization team members, temporal, spatial and social distances pertain to project duration, geographic dispersion and team size, respectively.

Hypothetical distance concerns whether an occurrence of an event is probable. In a multiorganization project, it indicates the perceived likelihood of "collaborative" activities (i.e. being constructive rather than destructive). A major obstacle of virtual collaboration is the risk involved in team member communication (e.g. ignorance, rejection, conflict) [18]. As well-accepted procedure leads to foreseeable outcome, hypothetical distance is closely related to procedure agreeability.

Mobile social media greatly reduces the temporal, spatial and social distances of collaborative activities to team members. The new communication platforms support both synchronous and asynchronous communication among team members no matter how dispersed they are. In addition, everyone can make messages visible by the others, which largely removes communicative barriers due to the traditional hierarchical structure of each organization. Such a flat structure of "all-channel" group communication minimizes the social distance [56]. The reduction of the three aspects of psychological distance manifests collaborative tool effectiveness.
The use of technology, however, does not automatically reduce hypothetical distance. Rather, it relies on how well communication patterns are established to avoid uncertainty and vulnerability.

Based on the understanding the virtual team development, a research model is proposed as shown in Figure 2. Laying the technical foundation, collaboration tool effectiveness is the exogenous variable as mobile social media overcome the temporal, spatial, and social dimensions of psychological distance. Communication patterns are established to regulate group collaboration, which also shapes the former in the process. Reflecting the hypothetical distance, procedure agreeability serves as the mediator between collaboration tool effectiveness and team performance variables including contextual performance and task performance. The socio-technical phenomenon is contextualized in virtual collaboration complexity comprising geographic dispersion, team size, and project duration, which serve as moderators.

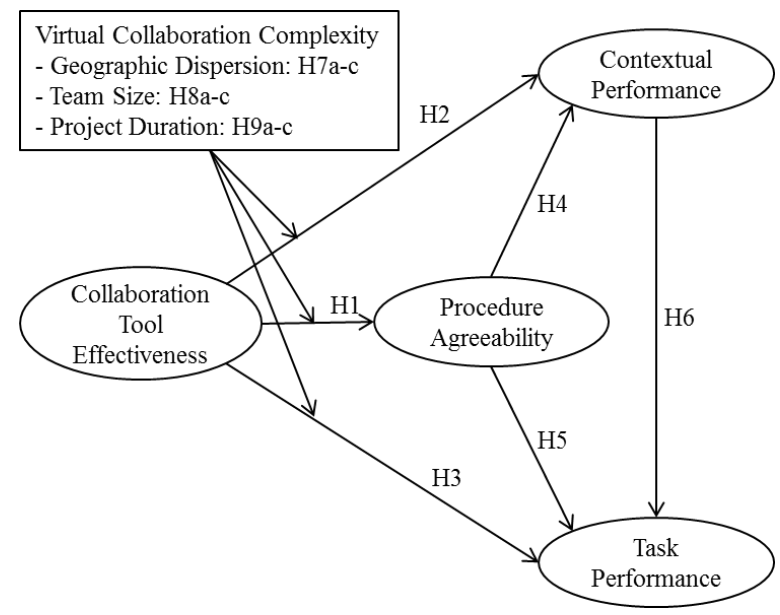

Figure 2. Research model

It is found that the satisfaction of team members regarding project process is closely related with their use of collaborative technologies, and eventually affects the results of teamwork [54]. In this study, procedure agreeability captures such an aspect of user perception regarding the technology-facilitated collaboration process. In group decision-support system (GDSS) research, it is also found that that user satisfactions with the technology, decision process and decision outcome are closely related with each other [51]. Multi-organization projects have much longer durations than GDSS sessions involving project conception and initiation, project definition and planning, project launch and execution, project performance and control, and project close [22]. As the use of collaboration tools like mobile social 
media permeates the whole process, collaboration tool effectiveness is likely to have a direct impact on procedure agreeability.

H1: Collaboration Tool Effectiveness has a positive effect on Procedure Agreeability.

A multi-organization project involves a large number of stakeholders within and across organizational boundaries, and team performance depends on not only task completion but also the establishment and maintenance of good working/social relationships. The two aspects of team performance, task performance and contextual performance, concerns the core processes of group functioning on job-specific and non-job-specific behaviors respectively [9]. Conway [15] argues that contextual performance is essentially the same with Organ's [48] recent conception of organizational citizenship behavior that coworkers show dedication and support to each other. In virtual teams, both contextual performance and task performance of members depend on how effectively they use collaboration tools to coordinate tasks and help each other.

H2: Collaboration Tool Effectiveness has a positive effect on Contextual Performance.

H3: Collaboration Tool Effectiveness has a positive effect on Task Performance.

In a virtual team highly depending on computermediated communication, it is essential that members agree with the way that they interact with each other through collaboration tools like mobile social media to engage in relationship building and task accomplishment $[60,23]$. When team members are satisfied with project processes (i.e. procedure agreeability), the group is likely to have a good cooperative atmosphere (i.e. contextual performance) that is conducive to the accomplishment of tasks (i.e. task performance) [43]. Thus, there is supposed to be a partial mediation between procedure agreeability and task performance through contextual performance.

H4: Procedure Agreeability has a positive effect on Contextual Performance.

H5: Procedure Agreeability has a positive effect on Task Performance.

H6: Contextual Performance has a positive effect on Task Performance.

Member dispersion defines a virtual team and poses a big challenge for collaborative effort [47]. In some cases, however, it may bring some unique benefits, such as enhanced innovation quality [40]. In a multi-organization project, the use of collaboration tools like mobile social media leads to the establishment of a shared mental model among geographically distributed team members, which enables collaborative effort [3]. The physical distances among team members shape the shared mental model in terms of social ties, rapport, and transactive memory that are critical for team performance [39]. Thus, geographic dispersion may make a difference in how collaboration tool effectiveness influences different aspects of group dynamics.

H7a: Geographic Dispersion moderates the relationship between Collaboration Tool Effectiveness and Procedure Agreeability.

H7b: Geographic Dispersion moderates the relationship between Collaboration Tool Effectiveness and Contextual Performance.

H7c: Geographic Dispersion moderates the relationship between Collaboration Tool Effectiveness and Task Performance.

Compared with smaller teams, it is harder for larger teams to control schedule, cost and quality [50]. On the other hand, big project teams usually have richer resources and may achieve more than medium and small ones when their collaborative efforts are well facilitated [70]. New collaboration tools like mobile social media make it technically easier to handle virtual teams of large sizes. Thus, team size may moderate the relationship between technology use and collaboration results [69].

H8a: Team Size moderates the relationship between Collaboration Tool Effectiveness and Procedure Agreeability.

H8b: Team Size moderates the relationship between Collaboration Tool Effectiveness and Contextual Performance.

H8c: Team Size moderates the relationship between Collaboration Tool Effectiveness and Task Performance.

Similar to team size, project duration is another risk factor for virtual teams. Compared with shortterm projects, long-term projects require more resources and managerial controls to cope with increased risks [50]. In IT outsourcing projects, for instance, project duration is found to have a negative impact on project success [38]. On the other hand, it takes time to develop the relations among virtual team members through technology facilitation [49]. For multi-organization projects, it is especially important for team members to establish mutual understanding and trust [58]. Thus, project duration may play different moderating roles in how collaboration tool effectiveness influences various aspects of group dynamics.

H9a: Project Duration moderates the relationship between Collaboration Tool Effectiveness and Procedure Agreeability. 
H9b: Project Duration moderates the relationship between Collaboration Tool Effectiveness and Contextual Performance.

H9c: Project Duration moderates the relationship between Collaboration Tool Effectiveness and Task Performance.

The use of mobile social media greatly reduces psychological distance in terms of temporal, spatial and social dimensions. Thus, it is likely that the hypothesized moderating effects turn out to be insignificant or opposite in the directions as commonly believed. For instance, geographic dispersion is usually considered a negative factor in traditional teams. In technology-enabled virtual teams, however, it may no longer have a negative impact, but even lead to some positive outcome (e.g. diversity and creativity). To accommodate different possibilities, the directions of moderating effects are not specified and they will be assessed with twotailed tests.

\section{Methodology}

\subsection{Research Design}

For testing hypothesized relationships, this study designs a survey to collect empirical observations. The target population is team members who use mobile social media as collaboration tools in multiorganization projects. First released in January 2011 by Tencent in China, WeChat is a mobile social media platform that supports services like texting, group chat, broadcast messaging, moments, voice/video call, photograph/video sharing, location exploration, payment and city service (https://en.wikipedia.org/wiki/WeChat). In China, therefore, WeChat has become a very popular collaboration tool for project team members to work together through multimedia and multimodal communication anywhere and anytime [17].

The target population comprises the members of multi-organization teams using WeChat. It is hard to find participants that meet both conditions using random sampling. As a practical compromise, a snowball sampling is used to collect data in China. The initial list was obtained from one advanced manager training center and two executive MBA programs. The contacts received a WeChat invitation that contained the survey link, and were also encouraged to distribute the message to other business associates that they know in person. Before filling out the questionnaire, each participant answered two filtering questions on whether s/he had been involved in any multi-organization projects and whether WeChat was used. This study does not differentiate the roles (e.g. leader, member) that participant plays due to the flat structure of multipleorganization project teams based on mobile social media.

\subsection{Subjects}

At the end of a two-month period, 273 valid responses were collected. The final pool of participants had actual experience of using WeChat in multi-organization projects, and they dispersed over 6 major cities (Shanghai, Guangzhou, Shenzhen, Xi'an, Jinan, and Nanjing) in China. Following the practice recommended by Armstrong and Overton [4] to assess selection bias, early and late responses were compared. There were no significant differences between the first 50 responses and last 50 responses on the averages of any variables. As the late respondents might hesitate to participate in comparison with early respondents, the lack of differences suggested no serious selection bias.

Gender distribution was largely balanced, with males a little bit more than females. More than half of the participants were under the age of 30 , and less than ten percent were above 40 . The roles that they play reflect typical team structure: most were at the operational level than those at the managerial and executive levels. In terms of duration of projects, more than two thirds were short-term projects within a year, and a little bit more than 10 percent were long-term projects lasting more than two years. Similarly, most of the teams were small or medium in size comprising fewer than 50 members, whereas 15\% had 50 or more members. The geographic dispersion of the multi-organization teams, on the other hand, was more balanced: a little bit more than half of the teams were located in the same region, whereas the others were distributed over different regions or across different countries.

\subsection{Measurement}

The psychometric instruments in the questionnaire were adapted from previous studies. The measures of collaboration tool effectiveness were based on IS effectiveness scale [12]. Procedure agreeability was measured with the items used in the studies by Green and Taber [27] and Briggs, Reinig and Vreede [10]. Contextual performance and task performance were measured with the scales from Farh and Cheng [24] and Van Scotter and Motowidlo [65]. The specific wording was adapted to the context of this study. 
For the four psychological constructs measured with Likert scale items, common method bias was assessed with Harman's one-factor test [53, 55]. Exploratory factor analysis showed that the first overall principal component accounted for $33.03 \%$ of total variance, less than half of $67.41 \%$ explained by the four major components of Eigen values greater than one. In confirmatory factor analysis, similarly, the default 4-factor model yielded chi-square to degree-of-freedom ratio of 2.92 , which was much smaller than 10.93 from the one-factor model, even smaller than 2.97 from the 5 -factor model with the additional overall factor. Thus, common method bias did not pose a threat as individual factors explained more variance than the overall factor.

\section{Results}

Table 1 reports measurement validation results. All coefficients Alpha were above the threshold of 0.7 , and the internal consistency reflects the convergent validity among each construct's indicators. Meanwhile, constructs are not supposed to be highly correlated for discriminant validity. In this study, the highest correlation coefficient was lower than the smallest square roots of average variance extracted (AVE). With the supporting evidence of measurement validity, the descriptive statistics of each construct were calculated and average responses showed no abnormal patterns.

Table 1. Measurement validation

\begin{tabular}{lcccccc}
\hline \hline Variable & $\alpha$ & $\mathrm{M}(\mathrm{SD})$ & 1 & 2 & 3 & 4 \\
\hline 1. CTE & .90 & $3.38(.92)$ & $\mathbf{. 8 2}$ & & & \\
2. PA & .90 & $3.35(.81)$ & .29 & $\mathbf{. 8 4}$ & & \\
3. CP & .89 & $4.00(.54)$ & .20 & .34 & $\mathbf{. 8 0}$ & \\
4. TP & .79 & $3.77(.62)$ & .19 & .45 & .57 & $\mathbf{. 7 9}$ \\
\hline
\end{tabular}

Note: The bolded diagonals of correlation matrix are the square roots of AVE. CTE-Collaboration Tool Effectiveness; PA-Procedure Agreeability; CPContextual Performance; TP-Task Performance.

Partial least square structural equation modeling (PLS-SEM) is an appropriate technique to test the research model that involves latent variables and contains both mediating and moderating relationships. Table 2 gives the standardized estimates of path coefficients. There was supporting evidence for two thirds of the hypothesized relationships. The estimates of the first six paths were all positive as hypothesized (H1-H6). Moderating relationships exhibited a mixture of positive and negative patterns, which is somewhat expected.
There was a partial mediation between collaboration tool effectiveness and contextual performance through procedure agreeability, but a full mediation in the case of task performance. Geographical dispersion and team size positively moderated the relationship between collaboration tool effectiveness and procedure agreeability, but project duration served as a negative moderator. For contextual performance, team size and project duration played opposite roles, negative and positive moderators, respectively. The only significant moderator in the case of task performance was project duration that negatively moderated its relationship with collaboration tool effectiveness.

Table 2. Hypothesis testing

\begin{tabular}{lll}
\hline \hline Hypothesis \& Path & Est. (ME) & \\
\hline H1: Tool $\rightarrow$ Procedure & $.291(.057)^{* * *}$ & $\mathrm{~S}$ \\
H2: Tool $\rightarrow$ Contextual & $.103(.063)^{*}$ & $\mathrm{M}$ \\
H3: Tool $\rightarrow$ Task & $.018(.035)$ & $\mathrm{N}$ \\
H4: Procedure $\rightarrow$ Contextual & $.306(.065)^{* * *}$ & $\mathrm{~S}$ \\
H5: Procedure $\rightarrow$ Task & $.269(.052)^{* * *}$ & $\mathrm{~S}$ \\
H6: Contextual $\rightarrow$ Task & $.493(.065)^{* * *}$ & $\mathrm{~S}$ \\
H7a: Geo $\times$ Tool $\rightarrow$ Procedure & $.142(.061)^{* *}$ & $\mathrm{~S}$ \\
H7b: Geo $\times$ Tool $\rightarrow$ Contextual & $.071(.059)$ & $\mathrm{N}$ \\
H7c: Geo $\times$ Tool $\rightarrow$ Task & $-.014(.038)$ & $\mathrm{N}$ \\
H8a: Size $\times$ Tool $\rightarrow$ Procedure & $.106(.054)^{* *}$ & $\mathrm{~S}$ \\
H8b: Size $\times$ Tool $\rightarrow$ Contextual & $-.154(.076)^{* *}$ & $\mathrm{~S}$ \\
H8c: Size $\times$ Tool $\rightarrow$ Task & $.032(.041)$ & $\mathrm{N}$ \\
H9a: Dur $\times$ Tool $\rightarrow$ Procedure & $-.147(.070)^{* *}$ & $\mathrm{~S}$ \\
H9b: Dur $\times$ Tool $\rightarrow$ Contextual & $.150(.073)^{* *}$ & $\mathrm{~S}$ \\
H9c: Dur $\times$ Tool $\rightarrow$ Task & $-.135(.064)^{* * *}$ & $\mathrm{~S}$ \\
\hline Note: S-supported; N-not supported. M-marginally & \\
supported. ${ }^{*}$ p $<0.1 ;{ }^{* *}-$ p $<0.05 ;{ }^{* * *}-\mathrm{p}<0.01$. &
\end{tabular}

\section{Discussions}

The findings yield some interesting insights and important implications. First of all, the salient mediating and moderating relationships support the conceptualization of virtual team development as a contextualized hierarchy in terms of technology use, norm formation, and team performance under the influence of project characteristics. The existing literature mainly examines the technological factors related to collaboration tools, such as usability and technology-task fit [57, 1]. This study fills the research gap between technology use and task performance by investigating group dynamics in the context of virtual collaboration complexity.

Specifically, the hierarchy of virtual team development is modeled as the direct and mediating 
relationships among collaboration tool effectiveness (exogenous variable), procedure agreeability (endogenous variable with one incoming path), contextual performance (two incoming paths) and task performance (three incoming paths). The results indicate partial mediation through procedure agreeability from collaboration tool effectiveness to contextual performance, but full mediation to task performance. This is explainable as task performance is further away from collaboration tool effectiveness than contextual performance in the hierarchy. Reflecting the hypothetical distance of collaborative activities to team members, procedure agreeability affects social interaction before task cooperation.

In addition, this study demonstrates that virtual team development is subject to the moderation of project characteristics. Similarly, all three moderators are salient for procedure agreeability, two for contextual performance, and only one for task performance. The closer an aspect of group dynamics is to collaboration tool effectiveness, the more affected their relationship is by virtual collaboration complexity. This makes sense because mobile social media as new-generation collaboration tools are able to overcome the temporal, spatial, and social aspects of psychological distance, which then leads to performance enhancement. Among the nine moderating effects, three were insignificant and the rest were half negative and half positive. Thus, the use of new technology largely mitigates the negative impacts of complexity factors.

Geographic dispersion positively moderates the relationship between collaboration tool effectiveness and procedure agreeability. Except for that, it does not have direct impacts on any aspects of group dynamics nor moderating effects on team performances. As the fundamental project characteristic that defines virtual teams and demands the use of mobile social media, geographic dispersion mainly makes a difference in how technology use affects norm formation. The further away the team members are from each other, the stronger the relationship becomes, as they are more dependent on mobile social media to communicate with each other. The use of social media is conducive to more open/flat structures so that team members can direct contact each other [67]. This is especially important for more dispersed virtual teams.

Team size, on the other hand, makes differences on procedure agreeability and contextual performance (but not task performance) through the interaction with collaboration tool effectiveness. The bigger a team is, it is harder for everyone to agree on how to carry out collaboration; yet effective collaboration tools like mobile social media may expedite norm formation. On the other hand, a smaller group for a multi-organization project means that a higher proportion of people do not know each other in person, which leads to a lower contextual performance. Yet the effective use of mobile social media as collaboration tools may reverse the trend.

Finally, project duration has significant moderating effects on all aspects of group dynamics. When a multi-organization project has a longer cycle, team members have more time to adjust to each other and complete tasks, albeit be more susceptible to personal conflicts. This explains its negative effect on contextual performance. A shorter project, on the other hand, brings a sense of urgency, and mobile social media is able to facilitate the collaboration process more effectively than traditional methods. Thus, collaboration tool effectiveness has stronger relationships with procedure agreeability and task performance when project duration is shorter. Of course, there is a lack of time for members to mingle with each other, leading to worse contextual performance.

For a multi-organization project, therefore, it is better off to strike a balance between project duration and team size, whereas geographic dispersion is mostly predetermined. With the help of mobile social media, multi-organization project managers may consider increasing team size to some extent and making project duration relatively short. This is somewhat contradictory to the conventional belief that a team should be kept as lean as possible, or member collaboration may easily get out of control. With the facilitation of new collaborative technologies, however, virtual team development becomes faster and smoother.

The findings provide some hints on the best practices of using mobile social media in multiorganization teams. Through the shared platform, team members join a group designated for a multiorganization project. The sooner communication patterns are established, the less confusion and delay there will be due to reduced hypothetical distance. Rule making and acceptance require the involvement of all team members, and such self-governance ensures free voices and flat structure to maximize the creativity and productivity. The reduced social distance makes team size no longer the major constraint of virtual collaboration. Together with minimized spatial distance from the use of mobile social media, experts all over the country and even from other parts of the world may be invited as formal or ad hoc members to address emerging issues. The equal and open environment is conducive to collaboration effectiveness and project success. Finally, the timely delivery of outcomes demands the 
reduction of temporal distance, which can be achieved by breaking down a big task into smaller tasks. With the due dates of closer tasks in sight, members are likely to be motivated and their attentions focused.

This study has limitations. WeChat is the single collaboration tool chosen for its high population penetration in China, which also explains why the participants are from the same country. Narrowing the scope down to one technology in one country helps filter out the extraneous variance induced by different technological characteristics and cultural/economic influences. Yet the generalizability of the findings may be questioned whether they are applicable to various collaboration tools used in different countries. The limitations point to the directions of future research.

\section{Conclusion}

This study examines virtual team development from collaboration tool use to group dynamics involving procedure, relationship and task in the context of virtual collaboration complexity along space, scale, and time dimensions. It hypothesizes and tests the direct and mediating relationships among collaboration tool effectiveness, procedure agreeability, contextual performance and task performance, as well as the moderating effects of geographic dispersion, team size, and project duration. The empirical evidence supports most of the hypothesized relationships, and sheds lights on the best practices of using emerging mobile social media to optimize virtual team performance.

\section{Acknowledgments}

This research was supported by the Humanities and Social Science Fund of the Ministry of Education of China (Grant NO. 13YJA630136).

\section{References}

[1] M. Aiken, L. Gu and J. Wang, "Task knowledge and task-technology fit in a virtual team", International Journal of Management, 30 (2013), pp. 3.

[2] A. M. Aladwani, "IT project uncertainty, planning and success: An empirical investigation from Kuwait", Information Technology \& People, 15 (2002), pp. 210-226.

[3] H. P. Andres, "Technology-mediated collaboration, shared mental model and task performance", Journal of Organizational and End User Computing (JOEUC), 24 (2012), pp. 64-81.
[4] J. S. Armstrong and T. S. Overton, "Estimating nonresponse bias in mail surveys", Journal of marketing research (1977), pp. 396-402.

[5] L. Backstrom, D. Huttenlocher, J. Kleinberg and X. Lan, Group formation in large social networks: membership, growth, and evolution, Proceedings of the 12th ACM SIGKDD international conference on Knowledge discovery and data mining, ACM, 2006, pp. 44-54.

[6] Y. Bar-Anan, N. Liberman and Y. Trope, "The association between psychological distance and construal level: evidence from an implicit association test", Journal of Experimental Psychology: General, 135 (2006), pp. 609.

[7] T. Bingham and M. Conner, The New Social Learning: Connect. Collaborate. Work, Association For Talent Development, Alexandria, VA, 2015.

[8] J. L. Blaskovich, "Exploring the effect of distance: An experimental investigation of virtual collaboration, social loafing, and group decisions", Journal of Information Systems, 22 (2008), pp. 27-46.

[9] W. C. Borman and S. J. Motowidlo, "Task performance and contextual performance: The meaning for personnel selection research", Human performance, 10 (1997), pp. 99-109.

[10] R. O. Briggs, B. A. Reinig and G.-J. de Vreede, "Meeting satisfaction for technology-supported groups an empirical validation of a goal-attainment model", Small Group Research, 37 (2006), pp. 585-611.

[11] I. Carboni and K. Ehrlich, "The effect of relational and team characteristics on individual performance: A social network perspective", Human Resource Management, 52 (2013), pp. 511-535.

[12] Y. E. Chan, S. L. Huff, D. W. Barclay and D. G. Copeland, "Business strategic orientation, information systems strategic orientation, and strategic alignment", Information systems research, 8 (1997), pp. 125-150.

[13] H. K. Cho, M. Trier and E. Kim, "The use of instant messaging in working relationship development: A case study", Journal of Computer - Mediated Communication, 10 (2005), pp. 00-00.

[14] D. R. Comer, "A model of social loafing in real work groups", Human Relations, 48 (1995), pp. 647-667.

[15] J. M. Conway, Distinguishing contextual performance from task performance for managerial jobs, American Psychological Association, 1999.

[16] T. Cooke-Davies, "The "real" success factors on projects", International journal of project management, 20 (2002), pp. 185-190.

[17] D. Cui, "Beyond "connected presence": Multimedia mobile instant messaging in close relationship management", Mobile Media \& Communication, 4 (2016), pp. 19-36.

[18] T. U. Daim, A. Ha, S. Reutiman, B. Hughes, U. Pathak, W. Bynum and A. Bhatla, "Exploring the communication 
breakdown in global virtual teams", International Journal of Project Management, 30 (2012), pp. 199-212.

[19] R. M. Davison, C. X. Ou, M. G. Martinsons, A. Y. Zhao and R. Du, "The communicative ecology of Web 2.0 at work: Social networking in the workspace", Journal of the Association for Information Science and Technology, 65 (2014), pp. 2035-2047.

[20] W. H. DeLone and E. R. McLean, "The DeLone and McLean model of information systems success: A ten-year update", Journal of Management Information Systems, 19 (2003), pp. 9-30.

[21] Y. Dittrich and R. Giuffrida, Exploring the role of instant messaging in a global software development project, 6th IEEE International Conference on Global Software Engineering (ICGSE), IEEE, 2011, pp. 103-112.

[22] W. R. Duncan, A guide to the project management body of knowledge, Project Management Institute, 1996.

[23] N. Ehsan, E. Mirza and M. Ahmad, Impact of computer-mediated communication on virtual teams' performance: An empirical study, International Symposium on Information Technology (ITSim). IEEE, 2008, pp. 1-8.

[24] J. Farh and B. Cheng, "An investigation of modesty bias in self-ratings of work performance among Taiwan workers", Chinese Journal of Psychology, 39 (1999), pp. 103-118.

[25] D. R. Forsyth, Group dynamics, Cengage Learning, New York, NY, 2009.

[26] P. A. Grabowicz, J. J. Ramasco, E. Moro, J. M. Pujol and V. M. Eguiluz, "Social features of online networks: The strength of intermediary ties in online social media", PloS one, 7 (2012), pp. e29358.

[27] S. G. Green and T. D. Taber, "The effects of three social decision schemes on decision group process", Organizational behavior and human performance, 25 (1980), pp. 97-106.

[28] V. Grover, S. R. Jeong and A. H. Segars, "Information systems effectiveness: The construct space and patters of application", Information \& Management, 31 (1996), pp. 177-191.

[29] B. Guerin, Social facilitation, Wiley Online Library, 2010.

[30] J. R. Hackman, Group influences on individuals in organizations, Consulting Psychologists Press, 1992.

[31] E. Harrin, Social media for project managers, Project Management Institute, 2010.

[32] J. Heerwagen, K. Kelly and K. Kampschroer, The Changing Nature of Organisations, Work, and Workplace, National Institute of Building Sciences, Washington, DC, 2007.

[33] M. A. Hogg and K. D. Williams, "From I to we: Social identity and the collective self", Group Dynamics: Theory, Research, and Practice, 4 (2000), pp. 81.
[34] S.-J. Huang and W.-M. Han, "Exploring the relationship between software project duration and risk exposure: A cluster analysis", Information \& Management, 45 (2008), pp. 175-182.

[35] S.-Y. Hung, A. H. Huang, D. C. Yen and C.-M. Chang, "Comparing the task effectiveness of instant messaging and electronic mail for geographically dispersed teams in Taiwan", Computer Standards \& Interfaces, 29 (2007), pp. 626-634.

[36] S. M. Jex and T. W. Britt, Organizational psychology: A scientist-practitioner approach, John Wiley \& Sons, 2014.

[37] J. Keyes, Social software engineering: development and collaboration with social networking, CRC Press, New York, NY, 2016.

[38] C. Koh, S. Ang and D. W. Straub, "IT outsourcing success: A psychological contract perspective", Information Systems Research, 15 (2004), pp. 356-373.

[39] J. Kotlarsky and I. Oshri, "Social ties, knowledge sharing and successful collaboration in globally distributed system development projects", European Journal of Information Systems, 14 (2005), pp. 37-48.

[40] N. Lahiri, "Geographic distribution of R\&D activity: how does it affect innovation quality?", Academy of Management Journal, 53 (2010), pp. 1194-1209.

[41] A. S. Leufkens and N. G. Noorderhaven, "Learning to collaborate in multi-organizational projects", International Journal of Project Management, 29 (2011), pp. 432-441.

[42] Y. J. Li, Designing collaborative workspaces for particular complex work settings, 2016.

[43] P. B. Lowry, N. C. Romano, J. L. Jenkins and R. W. Guthrie, "The CMC interactivity model: How interactivity enhances communication quality and process satisfaction in lean-media groups", Journal of Management Information Systems, 26 (2009), pp. 155-196.

[44] N. Melone, "A theoretical assessment of the usersatisfaction construct in information systems research", Management Science, 36 (1990), pp. 76 - 91.

[45] B. Mullen, C. Symons, L.-T. Hu and E. Salas, "Group size, leadership behavior, and subordinate satisfaction", The journal of general psychology, 116 (1989), pp. 155170.

[46] V. F. Nieva, E. A. Fleishman and A. Rieck, Team dimensions: Their identity, their measurement and their relationships, DTIC Document, 1985.

[47] M. B. O'Leary and J. N. Cummings, "The spatial, temporal, and configurational characteristics of geographic dispersion in teams", (2007).

[48] D. W. Organ, "Organizational citizenship behavior: It's construct clean-up time", Human performance, 10 (1997), pp. 85-97.

[49] C. X. Ou and R. M. Davison, "Shaping guanxi networks at work through instant messaging", Journal of 
the Association for Information Science and Technology, 67 (2016), pp. 1153-1168.

[50] K. E. Papke-Shields, C. Beise and J. Quan, "Do project managers practice what they preach, and does it matter to project success?", International journal of project management, 28 (2010), pp. 650-662.

[51] S. Paul, P. Seetharaman and K. Ramamurthy, User satisfaction with system, decision process, and outcome in GDSS based meeting: an experimental investigation, System Sciences, 2004. Proceedings of the 37th Annual Hawaii International Conference on, IEEE, 2004, pp. 3746.

[52] L. M. Peters and C. C. Manz, "Identifying antecedents of virtual team collaboration", Team Performance Management: An International Journal, 13 (2007), pp. 117129 .

[53] P. M. Podsakoff, S. B. MacKenzie, J.-Y. Lee and N. P. Podsakoff, "Common method biases in behavioral research: a critical review of the literature and recommended remedies", Journal of applied psychology, 88 (2003), pp. 879.

[54] B. A. Reinig, "Toward an Understanding of Satisfaction with the Process and Outcomes of Teamwork", Journal of Management Information Systems, 19 (2003), pp. 65-83.

[55] H. A. Richardson, M. J. Simmering and M. C. Sturman, "A tale of three perspectives: Examining post hoc statistical techniques for detection and correction of common method variance", Organizational Research Methods (2009).

[56] S. P. Robbins and T. A. Judge, Organizational Behavior, Pearson Education, Boston, MA, 2013.

[57] K. Rouibah and H. Hamdy, "Factors affecting information communication technologies usage and satisfaction: perspective from instant messaging in Kuwait", Journal of Global Information Management (JGIM), 17 (2009), pp. 1-29.

[58] E. Rusman, J. Van Bruggen, P. Sloep and R. Koper, "Fostering trust in virtual project teams: Towards a design framework grounded in a TrustWorthiness Antecedents (TWAN) schema", International Journal of HumanComputer Studies, 68 (2010), pp. 834-850.

[59] J. E. Scott, "The measurement of information systems effectiveness: evaluating a measuring instrument", ACM SIGMIS Database, 26 (1995), pp. 43-61.

[60] R. T. Sparrowe, R. C. Liden, S. J. Wayne and M. L. Kraimer, "Social networks and the performance of individuals and groups", Academy of management journal, 44 (2001), pp. 316-325.

[61] J. Y. Thong and C.-S. Yap, "Information systems effectiveness: A user satisfaction approach", Information Processing \& Management, 32 (1996), pp. 601-610.

[62] P. G. Trivellas and I. Santouridis, "The Impact of Management Information Systems' Effectiveness on Task Productivitythe Case of the Greek Banking Sector", International Journal of Computer Theory and Engineering, 5 (2013), pp. 170.

[63] Y. Trope and N. Liberman, "Construal-level theory of psychological distance", Psychological Review, 117 (2010), pp. 440-463.

[64] E. Turban, T.-P. Liang and S. P. Wu, "A framework for adopting collaboration 2.0 tools for virtual group decision making", Group decision and negotiation, 20 (2011), pp. 137-154.

[65] J. R. Van Scotter and S. J. Motowidlo, "Interpersonal facilitation and job dedication as separate facets of contextual performance", Journal of applied psychology, 81 (1996), pp. 525.

[66] L. Wainfan and P. K. Davis, Challenges in virtual collaboration: Videoconferencing, audioconferencing, and computer-mediated communications, Rand Corporation, 2004.

[67] B. D. Weinberg and E. Pehlivan, "Social spending: Managing the social media mix", Business horizons, 54 (2011), pp. 275-282.

[68] G. M. Wittenbaum and R. L. Moreland, "Small Group Research in Social Psychology: Topics and Trends over Time", Social and Personality Psychology Compass, 2 (2008), pp. 187-203.

[69] L.-R. Yang, J.-H. Chen and H.-W. Wang, "Assessing impacts of information technology on project success through knowledge management practice", Automation in Construction, 22 (2012), pp. 182-191.

[70] L.-R. Yang, C.-F. Huang and K.-S. Wu, "The association among project manager's leadership style, teamwork and project success", International journal of project management, 29 (2011), pp. 258-267.

[71] I. Zigurs and B. K. Buckland, "A theory of task/technology fit and group support systems effectiveness", MIS quarterly (1998), pp. 313-334. 